\title{
Modulation of radiochemoimmunotherapy-induced B16 melanoma cell death by the pan-caspase inhibitor zVAD-fmk induces anti-tumor immunity in a HMGB1-, nucleotide- and T-cell-dependent manner
}

\author{
N Werthmöller ${ }^{1}$, B Frey ${ }^{1}$, R Wunderlich ${ }^{1}$, R Fietkau ${ }^{1}$ and US Gaipl ${ }^{*, 1}$
}

One prerequisite that radiotherapy (RT) and chemotherapy (CT) result in anti-tumor immune responses is triggering of immunogenic cell death forms such as necroptosis. The latter is inducible by inhibition of apoptosis with the pan-caspase inhibitor zVAD-fmk. The design of multimodal therapies that overcome melanoma's resistance to apoptosis is a big challenge of oncoimmunology. As hints exist that immune stimulation by hyperthermia (HT) augments the efficacy of melanoma therapies and that tumors can be sensitized for RT with zVAD-fmk, we asked whether combinations of RT with dacarbazine (DTIC) and/or HT induce immunogenic melanoma cell death and how this is especially influenced by ZVAD-fmk. Necroptosis was inducible in poorly immunogenic B16-F10 melanoma cells and ZVAD-fmk generally increased melanoma cell necrosis concomitantly with the release of HMGB1. Supernatants (SNs) of melanoma cells whose cell death was modulated with zVAD-fmk induced an upregulation of the activation markers CD86 and MHCll on macrophages. The same was seen on dendritic cells (DCs), but only when zVAD-fmk was added to multimodal tumor treatments including DTIC. DCs of MyD88 KO mice and DCs incubated with SNs containing apyrase did not increase the expression of these activation markers on their surface. The in vivo experiments revealed that $z V A D$-fmk decreases the tumor growth significantly and results in a significantly reduced tumor infiltration of Tregs when added to multimodal treatment of the tumor with RT, DTIC and HT. Further, a significantly increased DC and CD8+ T-cell infiltration into the tumor and in the draining lymph nodes was induced, as well as an increased expression of IFN $\gamma$ by CD8+ T cells. However, zVADfmk did not further reduce tumor growth in MyD88 KO mice, mice treated with apyrase or RAG KO mice. We conclude that HMGB1, nucleotides and CD8+ T cells mediate ZVAD-fmk induced anti-melanoma immune reactions in multimodal therapy settings.

Cell Death and Disease (2015) 6, e1761; doi:10.1038/cddis.2015.129; published online 14 May 2015

The cancer immune editing concept raised by Schreiber and colleagues ${ }^{1}$ and the findings that distinct chemotherapeutic agents induce immunogenic cancer cell death forms ${ }^{2}$ opened our minds that standard tumor therapies alone and especially in combination with further immune therapies are capable of inducing anti-tumor immune responses. ${ }^{3}$ The phenotype of the tumor cells and the tumor microenvironment are altered during therapy and, thereby, the tumor might become visible for the immune system. ${ }^{4} \mathrm{~A}$ main prerequisite for induction of anti-tumor immunity is triggering of immunogenic tumor cell death forms. ${ }^{5}$

Apoptosis is non- or even anti-inflammatory. ${ }^{6}$ In contrast, necrotic cells bear per se a high inflammatory and immunogenic potential. Damage-associated molecular patterns (DAMPs) are released because the plasma membrane of necrotic cells is disturbed. ${ }^{7,8}$ Danger signals as the high mobility group protein B1 (HMGB1) and the nucleotide adenosine triphosphate (ATP) activate DCs, foster crosspresentation of antigens and consecutively the activation of T cells. ${ }^{9}$ DAMPs therefore link radio- and/or chemotherapyinduced local alterations of the tumor cells and subsequent systemic anti-tumor immune reactions. ${ }^{10,11}$ HMGB1 is mostly passively released by therapy-induced necrotic tumor cells. ${ }^{12}$ The activation of DCs by HMGB1 is induced by its binding to TLR2 or TLR4. ${ }^{13,14}$ HMGB1 is further required for the migration of maturing DCs. ${ }^{15}$ The nucleotide ATP is often actively emitted and acts on purinergic receptors, especially on P2RX7. ${ }^{16,17}$

Activation of DCs is crucial for the success of multimodal tumor treatments. ${ }^{18}$ Several preclinical and clinical studies have demonstrated that tumor cell death induced by radiochemotherapy in combination with intratumoral DC injection

\footnotetext{
${ }^{1}$ Department of Radiation Oncology, University Hospital Erlangen, Friedrich-Alexander-Universität Erlangen-Nürnberg, Germany

${ }^{*}$ Corresponding author: US Gaipl, Department of Radiation Oncology, Radiation Immunobiology, University Hospital Erlangen, Friedrich-Alexander-Universität ErlangenNürnberg, Universitätsstrasse 27, 91054 Erlangen, Germany. Tel: +49 913185 44258; Fax: +49 913185 39335; E-mail: udo.gaipl@uk-erlangen.de

Abbreviations: AnxA5, AnnexinA5; APC, antigen-presenting cell; ATP, adenosine triphosphate; CFSE, carboxyfluorescein succinimidyl ester; CT, chemotherapy; CTL, cytotoxic T lymphocyte; DAMP, damage-associated molecular patterns; DC, dendritic cell; DTIC, dacarbazine; ELISA, enzyme-linked immunosorbent assay; FITC, fluorescein isothiocyanate; GM-CSF, granulocyte macrophage colony-stimulating factor; Gy, gray; HMGB1, high mobility group protein B1; HT, hyperthermia; MDSC, myeloid derived suppressor cell; MLKL, mixed lineage kinase domain-like; MyD88, myeloid differentiation primary response gene (88); NK cells, natural killer cells; NLRP3, NOD-like receptor family, pyrin domain containing 3; PI, propidium iodide; RAG, recombination activating proteins; RIP, receptor-interacting protein; RCT, radiochemotherapy; RT, radiotherapy; SN, supernatant; TLR, toll like receptor; Treg, regulatory T cell; w/o, without; U, units; X-ray, ionizing irradiation; zVAD-fmk, carbobenzoxy-valyl-alanyl-aspartyl-[Omethyl]-fluoromethyl-ketone
}

Received 22.12.14; revised 17.3.15; accepted 06.4.15; Edited by G Amarante-Mendes 
induces strong anti-tumor immune responses in several tumor entities. ${ }^{19-21}$ These responses can be enhanced by hyperthermia $(\mathrm{HT})$. Mild $\mathrm{HT}$ is an additive therapy to radiotherapy (RT) and/or chemotherapy (CT) in which tumor tissue is locally heated to temperatures of $40-44{ }^{\circ} \mathrm{C}$ for a time period of $1 \mathrm{~h}$. HT fosters protein aggregation and aggravates radiation- and chemotherapy-induced repair of DNA damage. ${ }^{22}$ In addition, locally applied HT is capable of inducing systemic anti-tumor responses. $^{23}$

Melanoma is the most dangerous form of skin cancer and its response to CT and RT is poor. ${ }^{24}$ To overcome melanoma's resistance to apoptosis, the search for multimodal treatments that aim of inducing immunogenic cell death forms is a big challenge of innovative oncoimmunology, ${ }^{25}$ as much as to understand the mechanisms of therapy-induced immunogenic melanoma cell death. Nowadays, evidence has come up that necrosis as immunogenic cell death form can also occur in a programmed manner. ${ }^{26,27}$ Necroptosis is independent of caspases and mainly occurs when caspases are not activated or inhibited. ${ }^{28}$ The pan-caspase inhibitor zVAD-fmk has been shown to inhibit apoptosis and concomitantly foster necroptosis. ${ }^{29}$ Further, encouraging preclinical studies have been performed using caspase inhibitors to reduce apoptosis in neurological disease ${ }^{30}$ and to reduce angiogenesis in solid tumors. ${ }^{31}$ First hints exist that immune stimulation by $\mathrm{HT}$ is capable of augmenting the efficacy of CT and RT treatments in melanoma $^{32}$ and that solid tumors can be rendered more sensitive to radiation by treatment with the pan-caspase inhibitor zVAD-fmk. ${ }^{31}$ Meaningful data regarding potential clinical efficacy of caspase inhibitors such as zVAD-fmk will only be yielded if the cell death pathways stimulated in model systems reflect that triggered in patients. ${ }^{33}$ Therefore, we examined here for the first time whether combinations of the clinically relevant single dose of RT of 2 Gy with the only for metastatic melanoma FDA-approved CT agent dacarbazine (DTIC) or combinations with $\mathrm{HT}\left(41.5^{\circ} \mathrm{C}\right.$ for $\left.1 \mathrm{~h}\right)$ induce immunogenic melanoma cell death and how zVAD-fmk is capable of improving the melanoma's immunogenicity by modulating the therapy-induced melanoma cell death.

\section{Results}

Single treatments of melanoma cells with clinically relevant dosage of RT, DTIC or HT do not induce apoptosis or necrosis. The response of melanoma cells to ionizing irradiation applied in classical RT and to DTIC is often poor. ${ }^{24}$ First hints exist that HT is capable of augmenting the efficacy of RT and CT treatments also in melanoma. ${ }^{32,34} \mathrm{We}$ observed that single treatments of the melanoma cells with $\mathrm{RT}$, DTIC or HT do not significantly alter the percentage of apoptotic and necrotic cells (Figures $1 \mathrm{a}$ and $\mathrm{b}$ ).

\section{RT combined with HT enhances melanoma cell apoptosis} and necrosis. However, the percentage of apoptotic and necrotic melanoma cells was increased when RT and HT were given in combination, while necrosis dominated over apoptosis (Figures 1a and b). Administration of irradiation before HT (2 Gy+HT) was more efficient in cell death induction as the other way round ( $\mathrm{HT}+2 \mathrm{~Gy})$. Regarding the chemosensitization effect of HT, only apoptosis of melanoma cells was slightly, but significantly increased (Figure 1a). The highest percentage of apoptotic plus necrotic cells was achieved by combining RT with DTIC and HT (Figures 1a and b).

Necroptosis is inducible in melanoma cells and correlates with release of HMGB1. Blocking apoptosis with the

\section{b}
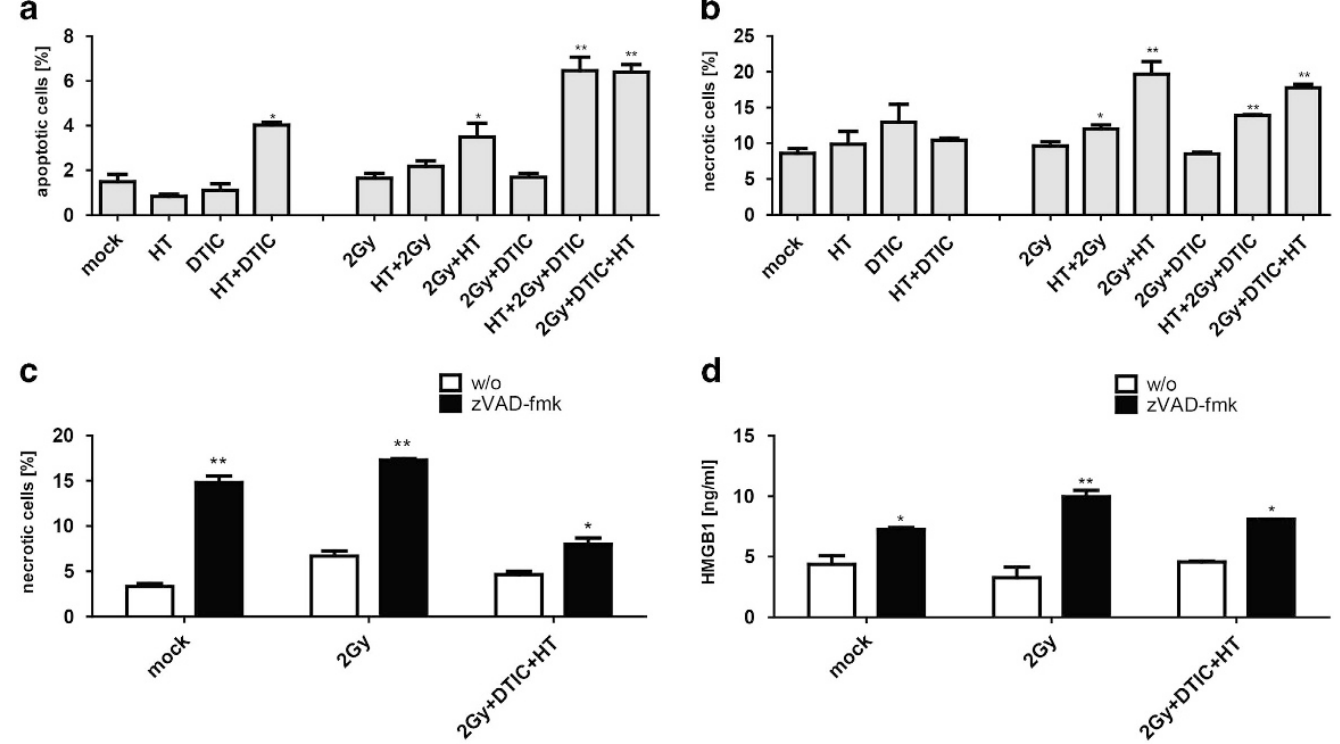

d
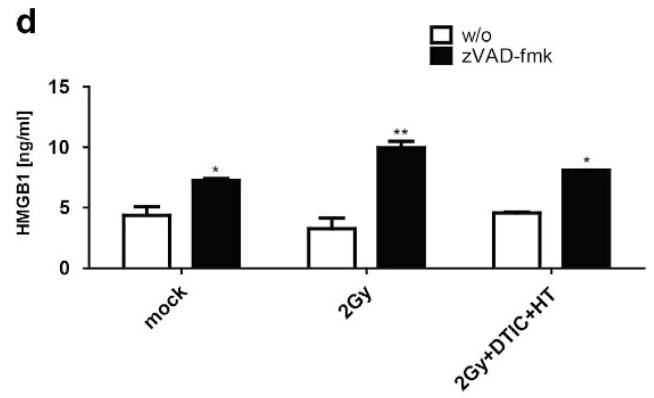

Figure 1 Cell death and release of the danger signal HMGB1 of melanoma cells after single and multimodal treatments with RT, DTIC and HT in the absence or presence of zVAD-fmk. The cell death forms of B16 mouse melanoma cells were analyzed with two color flow cytometry after staining with AnxA5-FITC and PI, $72 \mathrm{~h}$ (a and b) or $24 \mathrm{~h}(\mathbf{c})$ after the respective treatment. The release of HMGB1 was analyzed $24 \mathrm{~h}$ after the treatments with ELISA (d). Apoptotic cells are defined as AnxA5+/PI - and necrotic ones as AnxA5+/PI+. Representative data of one out of four experiments, each performed in triplicates, are presented as mean \pm S.D. ${ }^{*} P<0.05 ;{ }^{* *} P<0.01$ related to untreated (mock) B16 cells (a and $\mathbf{b}$ ) or to samples without (w/o) zVAD-fmk (c and d). DTIC at a concentration of $250 \mu \mathrm{M}$; Gy, Gray; HT with $41.5^{\circ} \mathrm{C}$ for $1 \mathrm{~h}$; zVAD-fmk, pan-caspase inhibitor. The order of irradiation with $2 \mathrm{~Gy}$ and $\mathrm{HT}$ indicated on the $x$ axis determines the chronology of the treatment 
pan-caspase inhibitor zVAD-fmk resulted in increased amounts of necrotic cells. This was independent of the death stimuli (Figure 1c). The addition of the necroptosis inhibitor nec-1 blocked the zVAD-fmk-induced tumor cell necrosis (Supplementary Figure 1A). Further, the mRNA expression of MLKL being as protein a component of the necroptosome was enhanced when zVAD-fmk was present (Supplementary Figure 1B). Fostering melanoma cell necrosis with zVAD-fmk increased the amount of HMGB1 in the SNs of the tumor cells. This increased release of HMGB1 correlated with the percentage of necrotic tumor cells (Figures $1 c$ and $d$ ).

Increased surface expression of MHCII and CD86 on macrophages by SNs of melanoma cells whose cell death was modulated with zVAD-fmk. As inhibition of caspases by zVAD-fmk has been suggested to be a promising strategy to enhance the efficacy of RT in solid tumors ${ }^{31}$ and because the immune system contributes to radiochemotherapy-induced tumor control, ${ }^{35}$ we next investigated whether SNs of melanoma cells that have been exposed to zVAD-fmk in addition to RT, DTIC, and/or HT impact on activation and function of macrophages and DCs.

SNs of neither mock-treated melanoma cells nor of treated ones altered the expression of the activation markers $\mathrm{MHCll}$ and CD86 on macrophages. However, the modulation of melanoma cell death by zVAD-fmk resulted in tumor cell SNs that induced a significant increased expression of $\mathrm{MHCI}$ and CD86 on the surface of macrophages, independent of the death stimulus (Figure 2). To prove that this is not a direct effect of zVAD-fmk on the immune cells, zVAD-fmk alone was added to macrophages or DCs. No influence on the expression of activation markers was observed neither for macrophages (Figure 2) nor for DCs (Figures 3b1 and b2).

Increased surface expression of MHCII and CD86 on DCs by SNs of melanoma cells whose cell death was induced by combination of RT, DTIC and HT and modulated with zVAD-fmk. In contrast to macrophages, the expression of $\mathrm{MHCI}$ and CD86 on the surface of DCs could not generally be increased by SNs of melanoma cells whose cell death was modulated by zVAD-fmk. However, cell death induction with DTIC in multimodal application with RT and HT together with zVAD-fmk led to significant increased expression of $\mathrm{MHCll}$ and CD86 on DCs (Figures 3a and b). This was in part dependent on HMGB1, because no upregulation of the activation markers was observed when using DCs of MyD88 KO mice (Figures $4 \mathrm{a} 1$ and b1) or when incubating the tumor cell SNs with antiHMGB1 antibody, respectively (Supplementary Figure 2). Further nucleotides impact on it, as incubation of the SNs with Apyrase also impaired the expression of these activation markers on DCs (Figures 4a2 and b2).

SNs of melanoma cells whose cell death was modulated with zVAD-fmk induce an increased secretion of TNFa by DCs. Contact of DCs with SNs of melanoma cells whose cell death was modulated by zVAD-fmk resulted in an increased TNFa secretion (Figure $3 c$ ). This was independent of the treatment just as the HMGB1 release (Figure 1d). The secretion of TNFa was dependent on HMGB1 and on
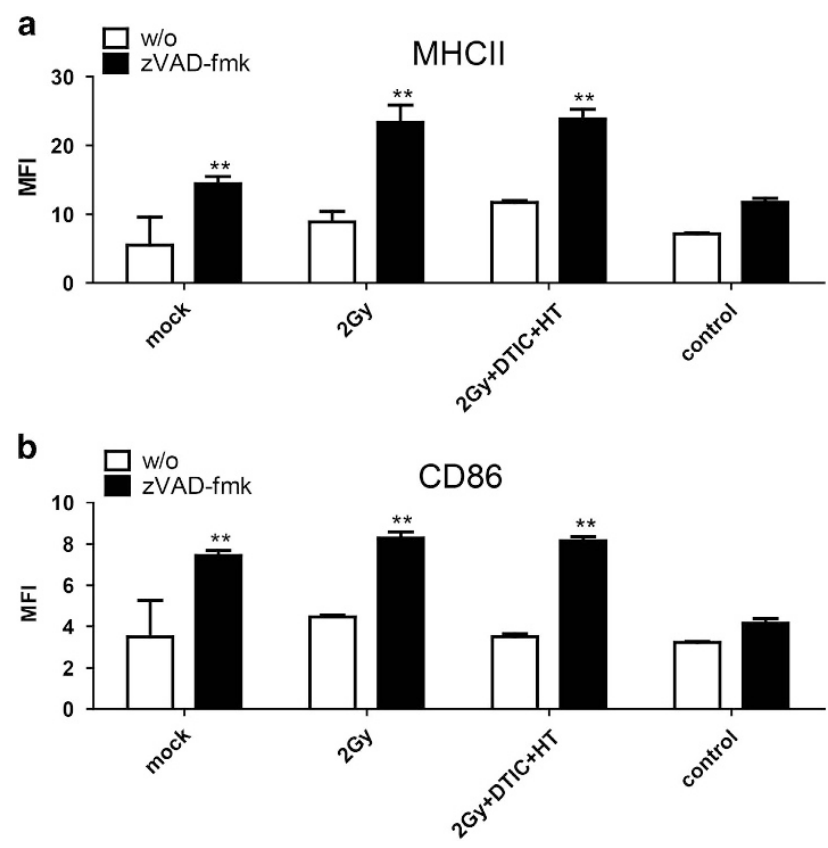

Figure 2 Surface expression of activation markers on macrophages after contact with SNs of treated melanoma cells in the presence or absence of ZVAD-fmk. The expression of the activation markers MHCII (a) and CD86 (b) on the surface of peritoneal mouse macrophages of C57/BL6 mice was analyzed by multicolor flow cytometry after contact with SNs of B16 mouse melanoma cells obtained $24 \mathrm{~h}$ after the respective treatments. The tumor cells were treated with ionizing irradiation with 2 Gy alone or in combination with the chemotherapeutic agent DTIC $(250 \mu \mathrm{M})$ and HT $\left(41.5^{\circ} \mathrm{C}\right.$ for $\left.1 \mathrm{~h}\right)$, in each case in the absence (w/o) or presence of the pan-caspase inhibitor ZVAD-fmk $(50 \mu \mathrm{M})$ (a and $\mathbf{b})$. Representative data of one out of three experiments, each performed in triplicates, are presented as mean \pm S.D. ${ }^{*} P<0.01$ related to samples without (w/o) inhibitor; MFI, mean fluorescence intensity; mock, SNs of untreated tumor cells; control, culture medium with or without ZVAD-fmk

nucleotides, because using DCs of MyD88 KO mice or incubating B16-F10 cell SNs with Apyrase did not alter the release of TNFa by DCs (Figures $4 \mathrm{c} 1$ and $\mathrm{c} 2$ ). Incubation of macrophages or DCs with SNs of treated melanoma cells did not impact on the phagocytosis of the dying melanoma cells by these immune cells. Further, the migration of macrophages or DCs towards the melanoma cells was also not influenced by this (data not shown).

Multimodal tumor treatment with RT, DTIC and HT in combination with zVAD-fmk results in long-lasting tumor growth retardation in dependence of HMGB1 and nucleotides. Treatment of B16 tumor-bearing mice with fractionated RT with a single dose of 2 Gy did not significantly delay tumor growth. The same was true for single treatment with zVADfmk or its combination with fractionated RT (Figure 5a). However, combination of fractionated RT with DTIC and HT resulted in significant reduction of the tumor volume. The most pronounced and long-lasting tumor growth inhibition was observed when zVAD-fmk was added to the multimodal treatment with fractionated RT, DTIC and HT (Figure 5a). Significant tumor growth retardation by combination of fractionated RT, DTIC and HT was also observed in MyD88 $\mathrm{KO}$ mice (Figure 5b) and when injecting Apyrase simultaneously in tumor-bearing wild-type mice (Figure 5c). 
a1

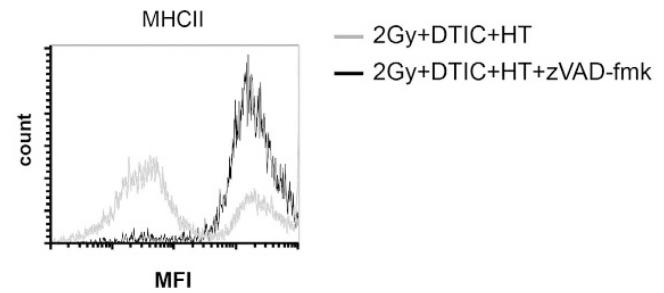

b1

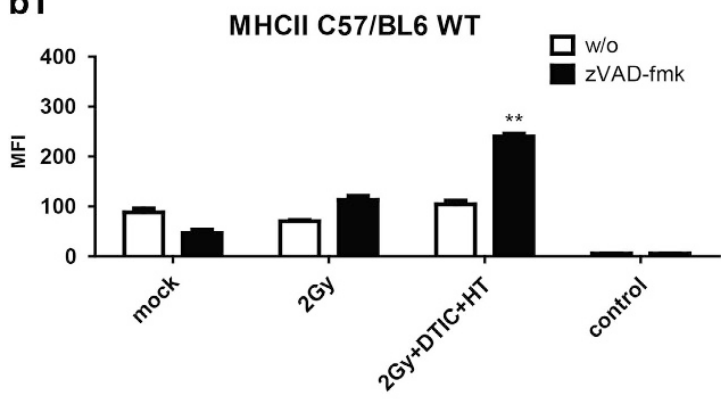

C

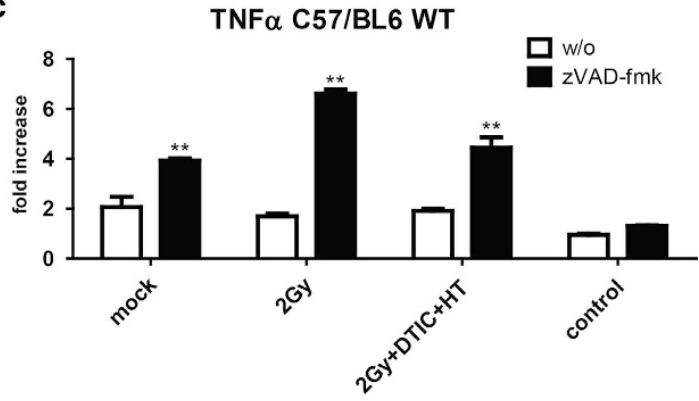

a2

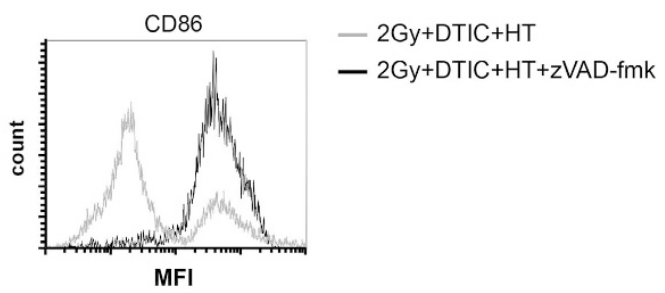

b2

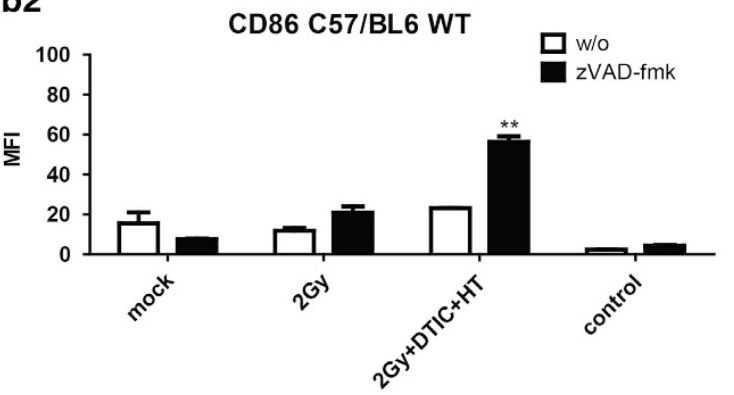

Figure 3 Surface expression of activation markers on DCs and release of TNF $\alpha$ by DCs after contact with SNs of treated melanoma cells in the presence or absence of zVAD-fmk. The expression of the activation markers MHCII (a1 and b1) and CD86 (a2 and b2) on the surface of bone marrow-derived DCs of C57/BL6 wild-type mice was analyzed by multicolor flow cytometry after contact with SNs of B16 mouse melanoma cells obtained $24 \mathrm{~h}$ after the respective treatments. The tumor cells were treated with ionizing irradiation with $2 \mathrm{~Gy}$ alone or in combination with the chemotherapeutic agent DTIC $(250 \mu \mathrm{M})$ and $\mathrm{HT}\left(41.5^{\circ} \mathrm{C}\right.$ for $\left.1 \mathrm{~h}\right)$, in each case in the absence (w/o) or presence of the pan-caspase inhibitor zVAD-fmk $(50 \mu \mathrm{M})$. In a1 and a2, representative histograms of the expression of MHCII or CD86 are displayed after contact of the DCs with SNs of melanoma cells that had been treated with RT, DTIC and HT in the absence (grey) or presence of ZVAD-fmk (black). The SNs of DCs after contact with the SNs of the melanoma cells were analyzed for TNF $\alpha$ by ELISA (c). Data of three experiments, each performed in triplicates, are presented as mean \pm S.D. ${ }^{* *} P<0.01$ related to samples without (w/o) inhibitor; MFI, mean fluorescence intensity; mock, SNs of untreated tumor cells; control, culture medium with or without ZVAD-fmk

However, the addition of ZVAD-fmk did not further reduce the tumor volume in MyD88KO mice as observed in the wild-type situation (Figures $5 \mathrm{~b}$ and $\mathrm{a}$ ) and it was less effective when Apyrase was simultaneously injected in wild-type mice (Figures $5 \mathrm{c}$ and $\mathrm{a}$ ).

zVAD-fmk impacts on immune cell infiltration into the tumor. A significant increased infiltration of both CD8+ and CD4+ $T$ cells into the tumor was observed after fractionated RT when combined with DTIC and HT. The addition of ZVADfmk further increased the percentage of infiltrating CD8+ T cells (Figure 6a1), but not of CD4+ T cells (Figure 6a2). The infiltration of DCs into the tumor was only enhanced by combination of RT with zVAD-fmk (Figure 6b). The infiltration of Tregs was significantly decreased after combined treatment both in the presence or absence of zVAD-fmk. The percentage of tumor-infiltrating MDSCs was decreased by all examined treatments (Figure 6d).
Multimodal tumor treatment with RT, DTIC and HT in combination with ZVAD-fmk increases infiltration of DCs and of CD8+ T cells into lymph nodes and the IFN $\gamma$ expression by CD8+ $T$ cells. For an effective immune response against the tumor not only the number, but also the phenotype including the activation status of the immune cells are crucial. Only multimodal tumor treatment with RT, DTIC and $H T$ in combination with zVAD-fmk increased the percentage of DCs in lymph nodes (Figure 7a), and especially that of CD8+ DCs (Figure 7b). The latter are specialized for cross-presentation of antigens. ${ }^{36}$ Nevertheless, the presentation of a tumor model antigen was as effective in the presence or absence of zVAD-fmk. All treatments enhanced the cross-presentation of OVA257264; only DCs of mock-treated mice presented less model tumor antigen (Figure 7c). However, only $\mathrm{T}$ cells of mice whose tumor was treated with RT, DTIC and HT in combination with zVAD-fmk expressed significant higher amounts of IFN $Y$ after re-stimulation (Figure 7d). 
a1

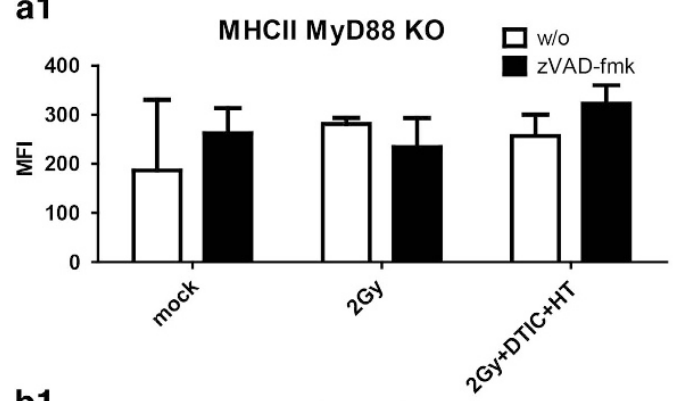

b1

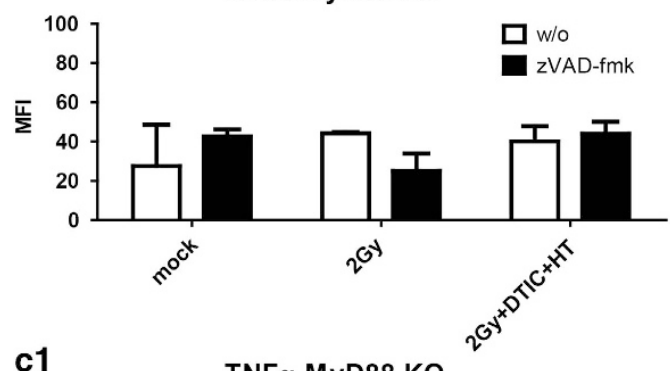

c1

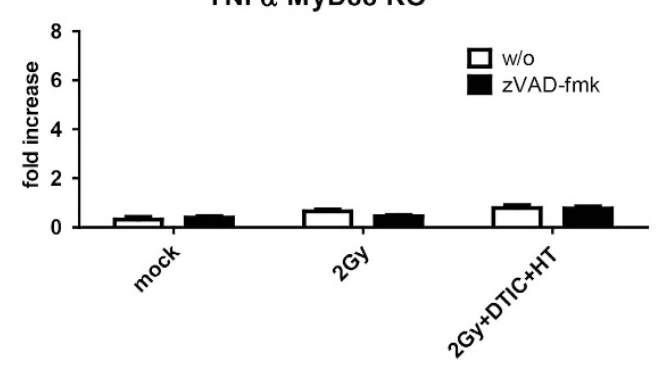

a2

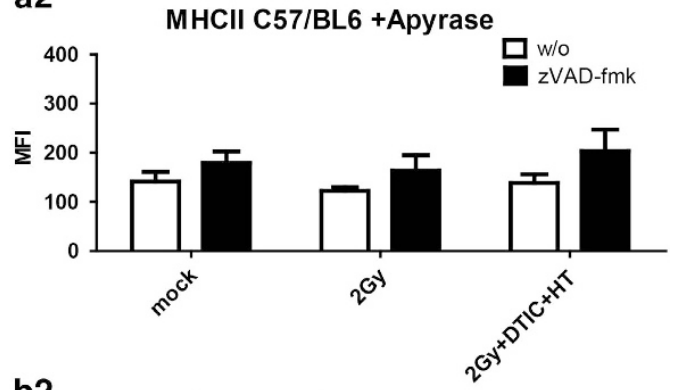

b2 CD86 C57/BL6 +Apyrase

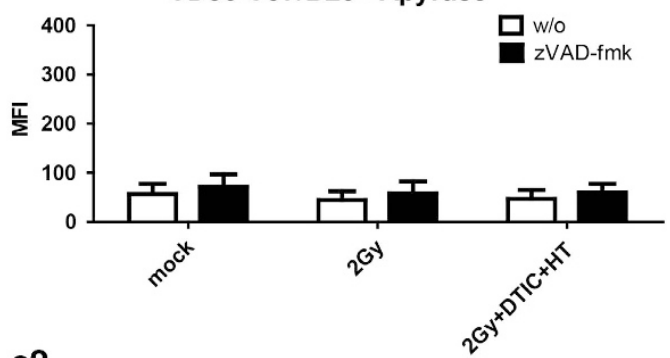

c2

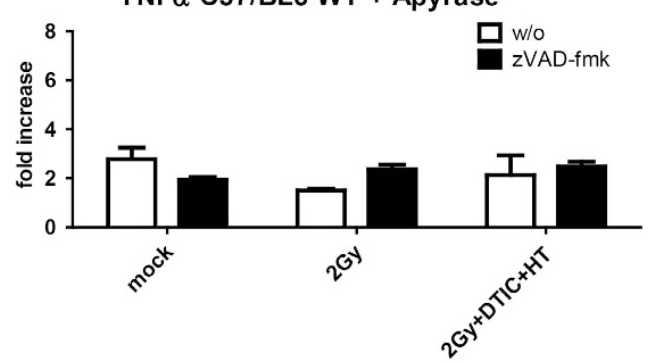

Figure 4 Impact of TLR signaling and nucleotides on the surface expression of activation markers on DCs and release of TNF $\alpha$ by DCs after contact with SNs of treated melanoma cells in the presence or absence of ZVAD-fmk. The expression of the activation markers MHCII (a1 and a2) and CD86 (b1 and b2) on the surface of bone marrowderived DCs of MyD88 KO mice (a1 and b1) or DCs of C57/BL6 wild-type mice in the presence of Apyrase (a2 and b2) was analyzed by multicolor flow cytometry, after contact with SNs of B16 mouse melanoma cells obtained $24 \mathrm{~h}$ after the respective treatments. The tumor cells were treated with ionizing irradiation with $2 \mathrm{~Gy}$ alone or in combination with the chemotherapeutic agent DTIC $(250 \mu \mathrm{M})$ and $\mathrm{HT}\left(41.5^{\circ} \mathrm{C}\right.$ for $\left.1 \mathrm{~h}\right)$, in each case in the absence (w/o) or presence of the pan-caspase inhibitor zVAD-fmk (50 $\left.\mu \mathrm{M}\right)$. The SNs of DCs after contact with the SNs of the melanoma cells were analyzed for TNF $\alpha$ by ELISA (c1 and c2). Data of three experiments, each performed in triplicates, are presented as mean \pm S.D. ${ }^{\star *} P<0.01$ related to samples without (w/o) inhibitor; MFI, mean fluorescence intensity; mock, SNs of untreated tumor cells

Multimodal tumor treatment with RT, DTIC and HT in combination with zVAD-fmk retards tumor growth in a T-cell-dependent manner. The enhanced infiltration and activation of CD8+ $T$ cells after multimodal tumor treatment and cell death modulation with zVAD-fmk had given hints that the observed tumor growth retardation by zVAD-fmk is dependent on $\mathrm{T}$ cells. To prove this, in vivo experiments were performed with B16-F10 tumor-bearing RAG-2-deficient (RAG KO) mice. Here, zVAD-fmk in combination with RT, DTIC and HT did not further decrease the tumor growth significantly in comparison with the multimodal treatment alone (Figure 8).

\section{Discussion}

Under certain clinical conditions, RT should be considered as treatment for melanoma. ${ }^{37} \mathrm{HT}$ as an adjuvant has been clinically proven to improve local control of malignant melanoma. ${ }^{38}$ Its chemoresistance can be overcome in a tumor cell-selective manner by interfering with antiapoptotic $\mathrm{Bcl}-2$ family members. ${ }^{39,40}$ Modulation of apoptotic cell death is therefore a promising strategy to combat cancer and inflammatory diseases in general. Here, caspases represent key targets for drug development as they are central in initiation and execution of cell death and in maturation of inflammatory cytokines. Pan-caspase inhibitors such as zVAD-fmk and IDN-6556 (F-03491390) have been proven in preclinical and currently running phase I/II clinical trials to be suitable drugs with manageable side effects. ${ }^{41,42}$

Besides local tumor control, systemic anti-tumor effects should be induced by modulation of cell death pathways. ${ }^{3,4,43}$ Although zVAD-fmk enhanced B16 necrosis (Figure 1c), it did not impact on the clonogenic potential of the tumor cells (Supplementary Figure 3A). However, a slight, but significant reduction of tumor cell proliferation induced by zVAD-fmk alone was observed (Supplementary Figure $3 B$ ). This suggests that besides its contribution to systemic immune activation against the tumor, zVAD-fmk also might locally act on the tumor. However, no further reduction of tumor growth by zVAD-fmk was observed when being combined with RT (Supplementary Figure 3). 
a

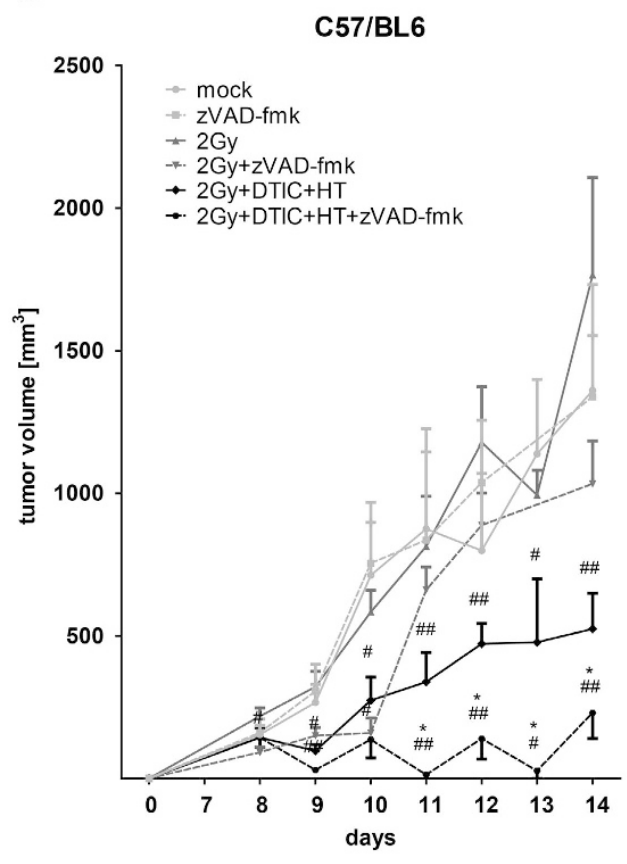

b

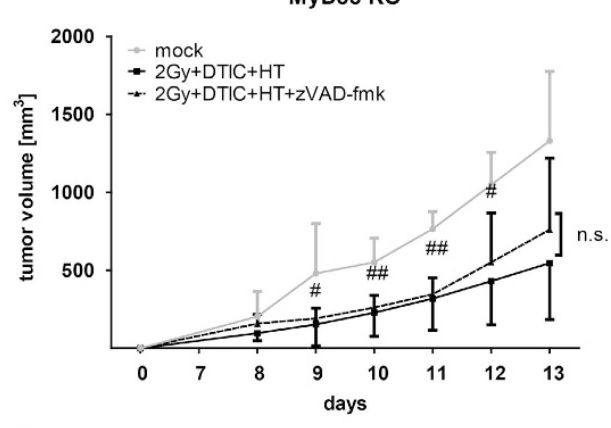

C

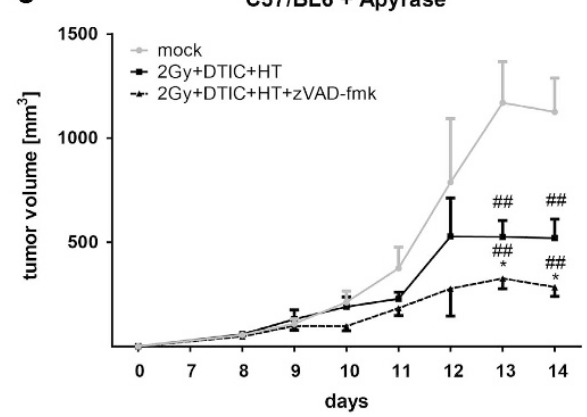

Figure 5 In vivo growth of B16 tumors after fractionated RT, DTIC and HT in the absence or presence of ZVAD-fmk and the impact of TLR signaling and nucleotides on it. The tumor growth of syngeneic B16 tumors in wild-type C57/BL6 (a), MyD88 KO (b) or wild-type C57/BL6 mice after systemic treatment with Apyrase (c) is displayed. The tumors were locally irradiated at days 8,9 and 10 with a clinically relevant single dose of $2 \mathrm{~Gy}$ using a linear accelerator. Two hours after the irradiation, DTIC (2 mg/mouse at day 8 and 10) and zVAD-fmk (2 mg/kg at day 8, 9 and 10) were injected i.p. Apyrase (c) was injected i.v. $1 \mathrm{~h}$ after irradiation (25 U/mouse at day 8$)$. HT was performed $4 \mathrm{~h}$ after irradiation at day 8 and 10. For this, the mice were anesthetized and the tumors were heated locally under temperature control to $41.5^{\circ} \mathrm{C}$ for 30 min using the BSD50 hyperthermia system. The tumor volume was monitored with an electronic caliper. Joint data of three independent experiments, each with three mice per group, are presented as mean \pm S.D. ${ }^{\#} P<0.05$; ${ }^{\#} P<0.01$ related to untreated tumors (mock); ${ }^{*} P<0.05$ related to tumors treated with RT, DTIC and HT in the absence of ZVAD-fmk; n.s., not significant

Multimodal treatment with RT, DTIC and HT resulted in the highest percentages of both apoptotic and necrotic melanoma cells. Especially a mixture of apoptosis and necrosis is supposed to possess high immunogenic potential, ${ }^{10}$ as also proven for melanoma vaccines consisting of lethally irradiated melanoma cells. ${ }^{44}$ Apoptotic cells release chemotactic factors to attract immune cells, ${ }^{45}$ and the release of DAMPs by necrotic cells then activates them. As the pan-caspase inhibitor zVAD-fmk has been shown to be capable of inducing immunogenic necrotic cell death forms in selected tumor entities such as fibrosarcoma ${ }^{46}$ and to better understand the molecular mechanisms of therapy-induced melanoma cell death, we were interested whether necroptosis is inducible in B16-F10 cells. Indeed, blocking B16 apoptosis with zVAD-fmk resulted in increased necrotic cell death. The induction of B16 necrosis by zVAD-fmk could be blocked by the necroptosis inhibitor, nec-1 (Supplementary Figure 1A), and addition of zVAD-fmk to irradiated B16 cells increased the mRNA level of MLKL (Supplementary Figure 1B). ${ }^{47}$

Also independent of the death stimuli, zVAD-fmk induced the release of HMGB1 by B16 cells (Figure 1d). Danger signals in general enhance maturation and antigen presentation of macrophages and DCs. These innate immune cells are the first ones that are recruited to the tumor. They regulate the cells of the adaptive immune system and are therefore crucial for success of an immune-based tumor therapy. ${ }^{48}$ The amount of released HMGB1 impacted especially on the increased expression of $\mathrm{MHCll}$ and CD86 on the surface on macrophages (Figure 2). In the case of DCs, the release of TNF $a$ also correlated with it (Figure $3 \mathrm{c}$ ). However, the expression of $\mathrm{MHCll}$ and CD86 on the surface on DCs was only increased after contact with SNs of B16 cells that had been treated with RT, DTIC, HT and zVAD-fmk. This indicates that, here, not only the amount of HMGB1 is crucial, but most likely also its redox state and further danger signals. ${ }^{49}$ A reductive environment may be important to maintain the bioactivity of HMGB1. In vivo, again, only combination of the multimodal treatment with zVAD-fmk and not only RT with zVAD-fmk resulted in highly significant tumor growth retardation (Figure 5). This suggests that other danger signals such as nucleotides in addition to HMGB1 are responsible for the therapy-induced immune activation (Figures $4 \mathrm{a} 2$ and b2, and Figure 5c). Further, the redox state of HMGB1 and not only the amount might also impact on it, because not only nucleotides are the reason for therapy-induced tumor growth retardation; even in the presence of apyrase, multimodal treatment with zVAD-fmk significantly further retards tumor growth when compared with multimodal treatment only (Figure $5 \mathrm{c}$ ). These results indicate that multiple mechanisms are responsible for induction of anti-tumor immunity by ZVAD-fmk when added to multimodal treatments. While early activation markers such as CD86 were increased on the surface of DCs, SNs of treated B16 cells did not impact on the expression of CD80 or CD40 on DCs (Supplementary Figure 4). ${ }^{50-52}$

As the upregulation of distinct activation markers was no longer observed on DCs of MyD88 KO mice (Figures 4a1 and b1) 
a1

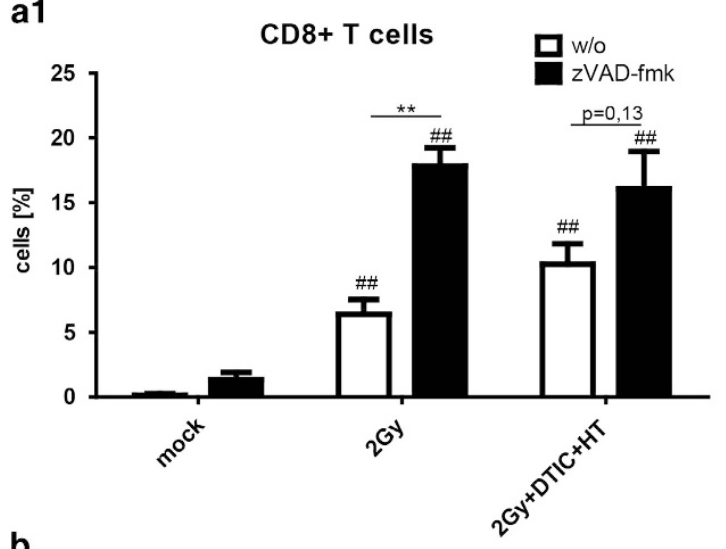

b

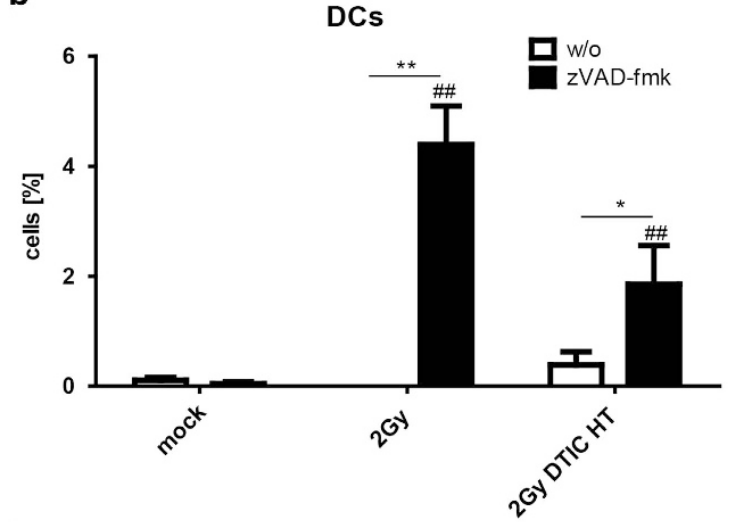

a2

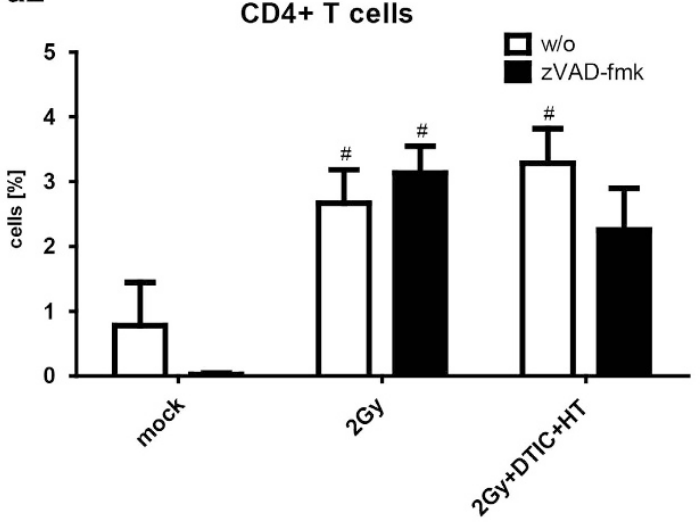

.

Tregs

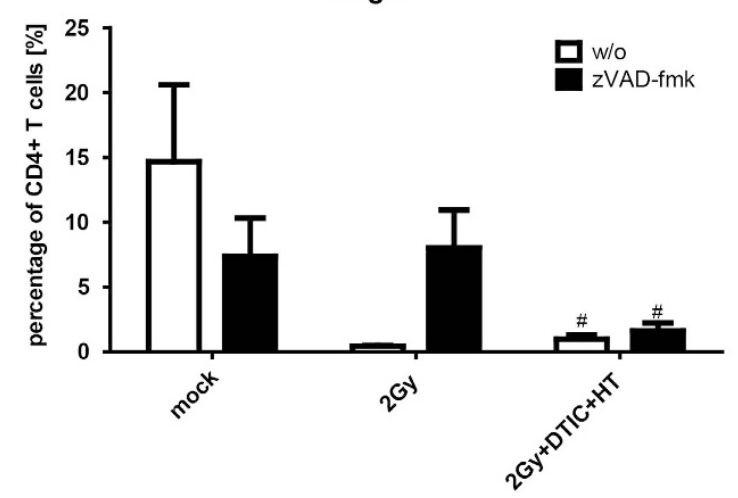

d

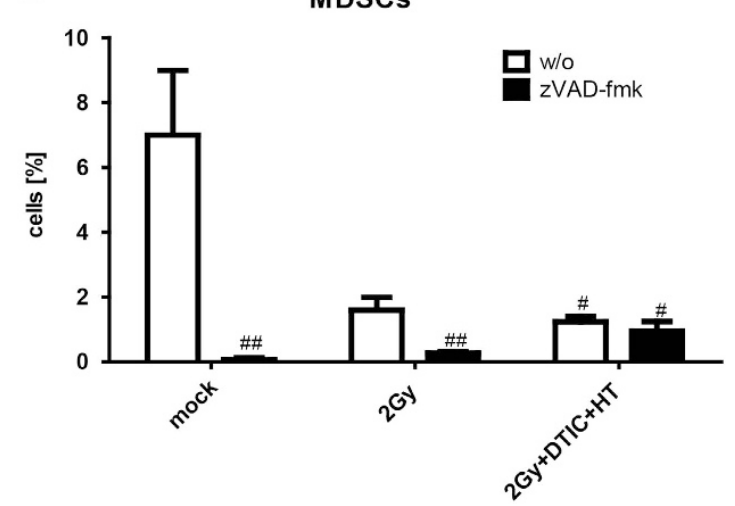

Figure 6 Immune cell infiltration into B16 tumors in C57/BL6 mice after fractionated RT, DTIC and HT in the absence or presence of zVAD-fmk. The infiltration of immune cells (CD8+ T cells (a1), CD4+ T cells (a2), DCs (b), Tregs (c) and MDSCs (d)) was analyzed by multicolor flow cytometry, $24 \mathrm{~h}$ after the last treatment of the tumors. The latter were before locally irradiated at days 8,9 and 10 with a clinically relevant single dose of 2 Gy using a linear accelerator. Two hours after the irradiation, DTIC (2 mg/mouse at day 8 and 10) and zVAD-fmk (2 mg/kg at day 8,9 and 10) were injected i.p. $\mathrm{HT}\left(41.5^{\circ} \mathrm{C}\right.$ for $\left.30 \mathrm{~min}\right)$ was performed $4 \mathrm{~h}$ after irradiation at day 8 and 10 . Joint data of three independent experiments, each with two mice per group, are presented as mean \pm S.D. ${ }^{\#} P<0.05$; ${ }^{\# \#} P<0.01$ related to untreated tumors (mock). ${ }^{*} P<0.05$, ${ }^{* \star} P<0.01$ related to tumors treated with RT, DTIC and HT in the absence of ZVAD-fmk

or SNs of tumor cells that had been incubated with Apyrase (Figures $4 \mathrm{a} 2$ and b2), we conclude that a combination of released HMGB1 and nucleotides like ATP is responsible for the activation of DCs. To confirm the impact of HMGB1 on activation of DCs, SNs of the treated tumor cells were supplemented with a neutralizing antibody against HMGB1 and added to the DCs afterwards. As shown in the Supplementary Figure 2, the increased expression of the activation markers on DCs was dependent on HMGB1. The latter activates immune cells via binding to the receptor for advanced glycation end products (RAGE) or especially to Toll-like receptor (TLR) 2 and TLR4. MyD88 KO mice have defects in TLR signaling and our results show that ZVAD-fmk did not further retard growth of B16 tumors treated with RT, DTIC and HT in these mice (Figure $5 b$ ), again indicating that HMGB1 in vivo is a key player in zVAD-fmk-induced anti-tumor immune responses.

Apyrase is a calcium-activated plasma membrane-bound ATP diphosphohydrolase that catalyzes the hydrolysis of nucleotides like ATP to AMP and inorganic phosphate. ${ }^{53}$ 
a

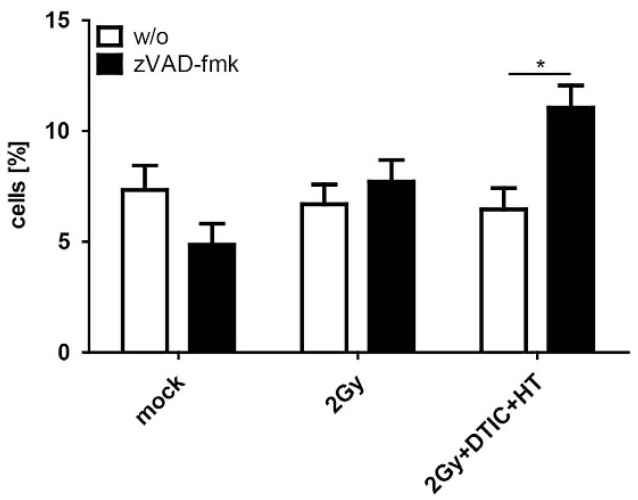

C

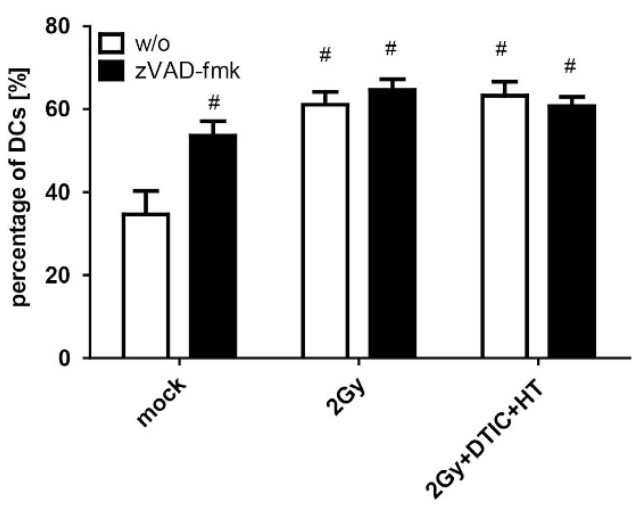

b

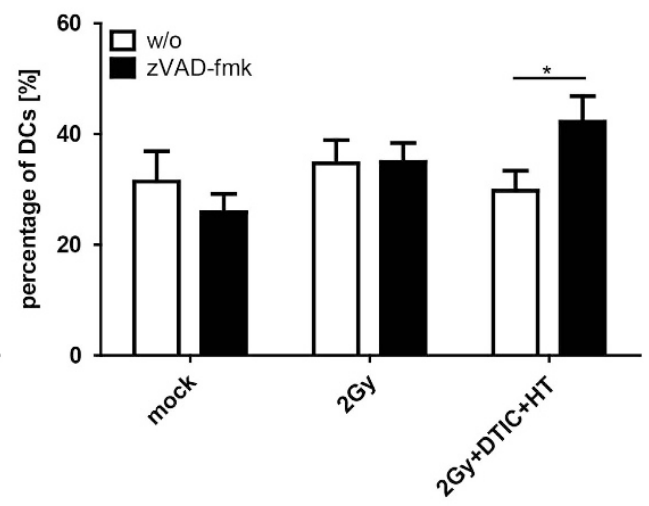

d

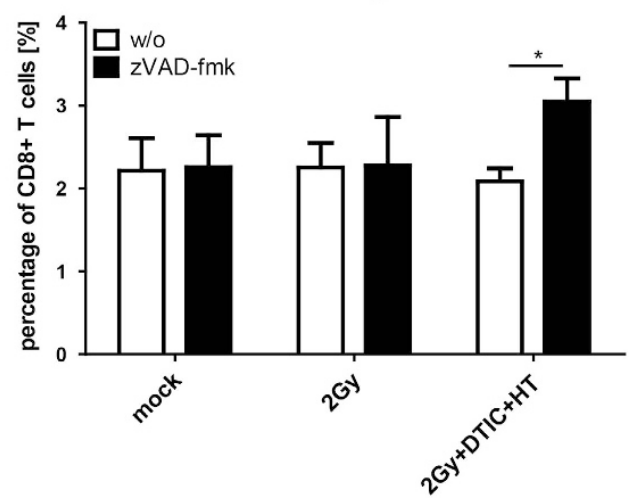

Figure 7 Infiltration of DCs into lymph nodes of B16-OVA tumor-bearing OT1 mice after fractionated RT, DTIC and HT in the absence or presence of ZVAD-fmk and related CD8+ T-cell activation. The infiltration of DCs (a) and especially that of CD8+ DCs (b) into the draining lymph nodes of OT1 mice was analyzed by multicolor flow cytometry, $96 \mathrm{~h}$ after the last treatment of the B16-OVA tumor according to the treatments already indicated in Figures 5 and 6 . Both presentation of SIINFEKL by DCs (c) and percentage CD8+ T cells expressing IFN $\gamma$ after ex vivo re-stimulation with OVA peptide were analyzed by multicolor flow cytometry, 7 days after the indicated treatment. Joint data of three independent experiments, each with two mice per group, are presented as mean \pm S.D. ${ }^{\#} P<0.05$ related to untreated tumors (mock); ${ }^{*} P<0.05$ related to tumors treated with RT, DTIC and HT in the absence of ZVAD-fmk

Removing extracellular nucleotides with apyrase treatment has been shown not only to prevent IL-1 $\beta$ accumulation, but also the production of inflammasome-independent cytokines such as TNF. ${ }^{54}$ The secretion of TNFa by DCs after contact with SN of B16 tumor cells that have been treated with zVADfmk was also dependent on both nucleotides and TLR signaling (Figures $4 c 2$ and $c 1$ ). As the half-life of zVAD-fmk is short $(<40 \mathrm{~min}),{ }^{55}$ a direct effect of the pan-caspase inhibitor on the immune cells is further excluded.

The in vivo studies demonstrated that combination of RT, DTIC and HT with zVAD-fmk induced the strongest tumor growth retardation in a HMGB1- and nucleotide-dependent manner (Figure 5). Fractionated irradiation alone did not affect the tumor growth, reflecting the radioresistance of melanoma also in our model system. While the triple treatment with RT, DTIC and HT in the absence of zVAD-fmk already induced a significant increased infiltration of CD8+ T cells into the tumor, zVAD-fmk in combination with RT further enhanced this (Figure 6a1). The infiltration of DCs into the tumor was only significantly enhanced when zVAD-fmk was given in combination with fractionated RT (Figure 6b). Tregs and MDSCs that exert immune suppression in melanoma ${ }^{56}$ were significantly reduced in the tumor, both after triple treatment in the presence or absence of ZVAD-fmk (Figures $6 c$ and d).

Of note is that only combination of RT, DTIC and HT with zVAD-fmk-induced increased amounts of DCs, and especially of CD8+ DCs which are specialized to cross-present antigen ${ }^{57}$ in the lymph nodes of OT1 mice (Figures 7a and b). However, zVAD-fmk in general fostered the presentation of the model antigen OVA257-264 by DCs, as it was also the case when treating the tumor with RT in single or multimodal settings (Figure 7c). However, the activation of CD8+ $\mathrm{T}$ cells, monitored by increased expression of IFN $\gamma$ after restimulation with OVA peptide, was only observed after treatment of the tumor with RT, DTIC and HT in the presence of zVAD-fmk (Figure 7d).

That $\mathrm{T}$ cells are involved in immune reactions against B16 tumors treated with RT, DTIC and HT in combination with zVAD-fmk was further underpinned by performing the in vivo experiments with RAG KO mice that lack functional $B$ and $T$ cells. No significant further tumor growth retardation was observed when zVAD-fmk was combined with the multimodal treatment (Figure 8).

To summarize, zVAD-fmk induced immunogenic melanoma cell necroptosis in vitro and tumor growth retardation in vivo 


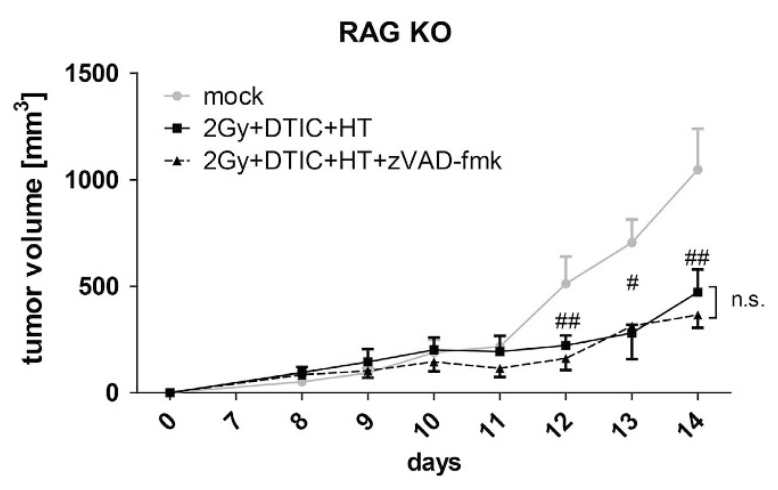

Figure 8 In vivo growth of B16 tumors in RAG KO mice after fractionated RT, DTIC and HT in the absence or presence of ZVAD-fmk. The growth of syngeneic B16 tumors in RAG KO mice is displayed. The tumors were either left untreated (mock) or were locally irradiated at days 8,9 and 10 with a clinically relevant single dose of $2 \mathrm{~Gy}$ using a linear accelerator. Two hours after the irradiation, DTIC $(2 \mathrm{mg} / \mathrm{mouse}$ at day 8 and 10$)$ and ZVAD-fmk (2 mg/kg at day 8,9 and 10) were injected i.p. Joint data of three independent experiments, each with two mice per group, are presented as mean \pm S.D. ${ }^{\#} P<0.01$ related to untreated tumors (mock). n.s., not significant

when combined with fractionated RT, DTIC and HT. This was dependent on HMGB1 and nucleotides. Activation of CD8+ T cells by DCs seems to be one key mechanism of ZVAD-fmktriggered anti-melanoma immune responses. Moretti et al. ${ }^{31}$ already demonstrated that ZVAD-fmk acts as radiosensitizer for lung and breast cancer cells. It significantly further retarded the growth of xenogeneic tumors treated with fractionated RT (5×2 Gy) and increased the expression of HMGB1 as observed in tumor tissue sections. Distinct irradiation schemes, chemotherapeutic drugs, HT and cell deathmodifying agents such as ZVAD-fmk bear high potential as immune-modulating agents besides their direct cytotoxic effects on the tumor cells. The abscopal effect, a phenomenon in which local RT in combination with further immune modulation $^{58}$ is associated with the regression of cancer at a distance from the irradiated site, ${ }^{4}$ raises the hope that multimodal treatments that induce an activation of immune cells will increase the survival of melanoma patients in the future. Such abscopal effects have already been clinically observed in patients with metastatic lung cancer and melanoma treated with ipilimumab and $\mathrm{RT}^{.59,60}$ Our data suggest including ZVAD-fmk in radiochemoimmunotherapy treatment protocols of melanoma to foster the induction of immunogenic melanoma cell death and concomitantly T-cellmediated anti-melanoma immunity.

\section{Materials and Methods}

Cell culture. The mouse melanoma cell lines B16-F10 and B16-OVA (ATCC, Manassas, VA, USA) both derived from C57/BL6 mice were cultured in RPMI 1640 medium with stable glutamine (Biochrom, Berlin, Germany), supplemented with $10 \%$ heat-inactivated fetal bovine serum (Biochrom), $100 \mathrm{U} / \mathrm{ml}$ penicillin and $100 \mu \mathrm{g} / \mathrm{ml}$ streptomycin (Gibco, Carlsbad, CA, USA). The cells were tested negatively for mycoplasma contamination and maintained in $5 \% \mathrm{CO}_{2}$ atmosphere at $37^{\circ} \mathrm{C}$ and $95 \%$ relative humidity. The cells were used when they reached $90 \%$ confluence.

Treatment of the melanoma cells. The tumor cells were irradiated with a X-ray generator $(120 \mathrm{kV}, 22.7 \mathrm{~mA}$, variable time; GE Inspection Technologies, Hürth, Germany) with a single dose of 2 Gy, representing a clinically relevant single dose in RT of tumors. The routinely applied and only FDA-approved chemotherapy drug for metastatic melanoma DTIC (Sigma-Aldrich, Munich, Germany) was used in the concentration of $250 \mu \mathrm{M}$ and added in parallel to the irradiation of the tumor cells. The pan-caspase inhibitor carbobenzoxy-valyl-alanyl-aspartyl-[Omethyl]fluoromethyl-ketone (zVAD-fmk, Bachem, Weil am Rhein, Germany) was used at a concentration of $50 \mu \mathrm{M}$ and the necroptosis inhibitor necrostatin-1 (nec-1) at a concentration of $10 \mu \mathrm{M}$. Both inhibitors were solved in dimethyl sulfoxide and added directly after the irradiation. For HT, the melanoma cells were treated in a homemade device placed in a cell incubator as described previously. ${ }^{61}$ The variations of the temperature during the treatment were less than $0.2^{\circ} \mathrm{C}$. The cells remained at stable $41.5^{\circ} \mathrm{C}$ for $1 \mathrm{~h}$. For combined applications, the tumor cells were stored at $37^{\circ} \mathrm{C}$ for $4 \mathrm{~h}$ between RT and/or CT and HT treatment, as it is the maximal time frame between the treatments in clinical application. For degradation of extracellular ATP and nucleotides in general, the cells were incubated with $10 \mathrm{U} / \mathrm{ml}$ medium Apyrase right after $\mathrm{HT}$.

Analyses of cell death forms. Cell death and forms were determined by AnnexinA5 (Anx5)-fluorescein isothiocyanate (FITC) and propidium iodide (PI) staining. For analysis of cell death, $1 \times 10^{5}$ cells were transferred in $400 \mu \mathrm{l}$ of Ringer's solution (B. Braun, Melsungen, Germany) containing $0.2 \mu \mathrm{g}$ AnxA5-FITC and $0.4 \mu \mathrm{g} \mathrm{Pl}$. After $30 \mathrm{~min}$ of incubation at $4^{\circ} \mathrm{C}$ in the dark, the samples were analyzed by flow cytometry. AnxA5 protein was expressed and produced in 293 human embryonic kidney cells (FreeStyle 293 Expression System, Life Technologies, Regensburg, Germany) and purified (Life Technologies, GENEART). Labelling with FITC was performed with the FluoroTag FITC Conjugation Kit (Sigma Aldrich, St. Louis, MO, USA) according to the manufacturer's instructions. Doublenegative cells were defined as viable, Anx $\mathrm{A5}^{+} / \mathrm{PI}^{-}$as apoptotic, and $A n \times \mathrm{AS}^{+} / \mathrm{PI}^{+}$as necrotic ones.

Clonogenic assay and cell growth. The effect of ZVAD-fmk on the radiosensitivity of B16-F10 melanoma cells was assessed in a clonogenic assay. Shortly, cells were plated in triplicates in $60 \mathrm{~mm}$ dishes (Nunc Thermo Fisher, Waltham, MA, USA) at concentrations estimated to yield $40-150$ colonies per dish. The cells were irradiated with $1,2,4,6,8$ or 10 Gy $24 \mathrm{~h}$ after seeding. Directly after irradiation, zVAD-fmk $(50 \mu \mathrm{M})$ was added. After incubation for $\sim 2$ weeks, cells were fixed with methylene blue (Sigma-Aldrich, Munich, Germany) for $30 \mathrm{~min}$. Colonies with $>50$ cells were scored. The growth of the melanoma cells in the presence or absence of ZVAD-fmk was monitored by counting the cells with a Neubauer chamber.

Quantitative real-time PCR for analysis of MLKL expression. RNA was isolated from irradiated melanoma cells by using peqGOLD TriFast (Peqlab, Erlangen, Germany). cDNA was generated from the RNA by using QuantiTect reverse transcription kit (Qiagen, Venlo, the Netherlands). The expression levels of mixed lineage kinase domain-like (MLKL) mRNA were measured by real-time RT-PCR. For the qPCR experiments, SsoFast EvaGreen Supermix (Bio-Rad, München, Germany) and the Bio-Rad CFX Real-Time System were used. The used primer sequences are forward: 5'- TAGCCGGAGGCTACCAA GTAAAGC-3', reverse:5'-TGTCCGGCTGATGGAATTCTGTG-3'. mRNA levels were normalized to actin.

Isolation of peritoneal macrophages. Peritoneal macrophages were isolated from C57/BL6 mice. For this purpose, $2.5 \mathrm{ml}$ of $4 \%(\mathrm{w} / \mathrm{v})$ of Brewer's thioglycollate broth was injected into the peritoneal cavity as described previously by Schleicher et al. ${ }^{62}$ Four days after the injection, the peritoneum was washed with $10 \mathrm{ml}$ PBS (Gibco) and the macrophages were cultured in RPMI 1640 medium with stable glutamine (Biochrom), supplemented with 10\% heat-inactivated fetal bovine serum (Biochrom), $100 \mathrm{U} / \mathrm{ml}$ penicillin and $100 \mu \mathrm{g} / \mathrm{ml}$ streptomycin (Gibco) and characterized by flow cytometry with preceding F4/80 staining.

Generation of bone marrow-derived DCs. Generation of bone marrowderived DCs was performed according to the protocol of Lutz et al. ${ }^{63}$ Shortly, bone marrow cells were isolated from femur and tibiae of 8-10-week-old C57/BL6 mice by flushing the cleaned bones with RPMI 1640 medium. The bone marrow cells were then cultured in DC medium (RPMI 1640) medium containing 10\% heatinactivated $\left(30 \mathrm{~min}\right.$ at $\left.56^{\circ} \mathrm{C}\right) \mathrm{FBS}, 100 \mathrm{U} / \mathrm{ml}$ penicillin, $100 \mu \mathrm{g} / \mathrm{ml}$ streptomycin, $0.1 \%$ $\beta$-mercaptoethanol $(50 \mathrm{mM})$ and freshly added $200 \mathrm{U} / \mathrm{ml}$ mouse GM-CSF. Cells $\left(2 \times 10^{6}\right)$ suspended in $10 \mathrm{ml} \mathrm{DC}$ medium were seeded in $100 \mathrm{~mm}$ bacteriological petri dishes. At day $3,10 \mathrm{ml}$ of fresh DC medium were added. At day 6 , half of the $\mathrm{SN}$ was collected and centrifuged ( $350 \times \mathrm{g}, 5 \mathrm{~min}$, room temperature). Thereafter, the cell pellet was re-suspended in $10 \mathrm{ml}$ fresh DC medium and returned to the plate. The DCs were harvested at day 8 and used for the activation analyses. 
Analyses of expression of activation markers on macrophages and DCs. Isolated peritoneal macrophages or bone marrow-derived DCs $\left(5 \times 10^{5}\right)$ were co-incubated in 6-well suspension cell plates for $16 \mathrm{~h}$ with $1 \mathrm{ml}$ of SNs obtained from B16-F10 tumor cells, $24 \mathrm{~h}$ after the respective single or multimodal treatments. Afterwards, the cells were solved with accutase and, to avoid unspecific binding of the staining antibodies to Fc-receptors, incubated for $10 \mathrm{~min}$ at $4^{\circ} \mathrm{C}$ with Fc-blocking reagent (eBioscience, Frankfurt, Germany). The immune cells were then stained for $30 \mathrm{~min}$ at $4^{\circ} \mathrm{C}$ with the following fluorescence-labeled antibodies: MHCll-e450 (eBioscience), CD80-PE (BD Pharmingen, New York City, NY, USA), CD86-Alexa Fluor700 (BD Pharmingen) and CD40-APC (eBioscience). Incubation of the cells with just medium, medium with DTIC or ZVAD-fmk served as controls. The hereby detected mean fluorescence intensity values after antibody staining were substracted from those resulting after contact of the immune cells with SNs of untreated or treated B16-F10 tumor cells.

Analyses by multicolor flow cytometry were performed with a Gallios Flow Cytometer (Beckman Coulter Inc., Krefeld, Germany).

Detection of secreted TNFa. TNF $\alpha$ that was secreted by activated macrophages or DCs was analyzed with a specific enzyme-linked immunosorbent assay (ELISA) kit (Biolegend, San Diego, USA) according to the manufacturer's instructions. For this, SNs of DCs or macrophages were collected $16 \mathrm{~h}$ after coincubation with SNs of the melanoma cells.

Detection of the danger signal HMGB1. The detection of of HMGB1 in SNs of the tumor cells was performed with the ELISA Kit II (Shino-Test Corporation, Tokyo, Japan) according to the manufacturer's instructions. Anti-HMGB1 antibody (Lifespan Biosciences, Nottingham, United Kingdom ) was used to block HMGB1 in the tumor cell SNs for selected experiments.

Induction of B16 melanomas in C57/BL6, MyD88 KO or RAG KO mice. Eight-week-old female C57/BL6, MyD88 KO or RAG KO mice were used for the in vivo experiments. B16-F10 cells $\left(10^{6}\right)$, solved in $200 \mu$ l Ringer's solution, were injected at day 0 into the right shaved flank of the mice. The tumor volumes were monitored over the days. For this, width and length were measured using a digital caliper and tumor volume was calculated according to the following formula: volume $\left(\mathrm{mm}^{3}\right)=0.5 \times$ width $^{2}\left(\mathrm{~mm}^{2}\right) \times$ length $(\mathrm{mm}){ }^{64}$

Treatment of B16 melanoma-bearing mice with ionizing irradiation, DTIC, HT, zVAD-fmk and Apyrase. At day 8, 9 and 10 after tumor induction, RT was performed. To irradiate the tumor-bearing mice, we manufactured a Plexiglas box which allows the irradiation of three mice at once. The mice were anesthetized before placing them into the box. For the irradiation procedure, the mice were kept under Isoflurane anesthesia to avoid moving of the mice. The tumors were locally irradiated at the indicated days with a clinically relevant single dose of 2 Gy using a linear accelerator (PRIMART, Siemens, Munich, Germany). The planning of the irradiation was conducted using a computer tomography image of the irradiation box and tumor-bearing mice with Philips pinnacle software (Best, Netherlands) to obtain an optimal target volume. To further protect normal tissue, the gantry of the $6 \mathrm{MV}$ linear accelerator was drifted to 340 degree. Two hours after the irradiation DTIC ( $2 \mathrm{mg} / \mathrm{mouse}$ at day 8 and 10 ) and zVAD-fmk ( $2 \mathrm{mg} / \mathrm{kg}$ at day 8 , 9 and 10$)$ were injected i.p. Apyrase was injected i.v. $1 \mathrm{~h}$ after irradiation $(25 \mathrm{U} /$ mouse at day 8 ). $\mathrm{HT}$ was performed $4 \mathrm{~h}$ after irradiation at day 8 and 10 . For this, the mice were anesthetized and the tumors were heated locally under temperature control to $41.5^{\circ} \mathrm{C}$ for 30 min using the BSD50 hyperthermia system.

All mice were bred under sterile atmosphere at the animal facility of the FriedrichAlexander-Universität Erlangen-Nürnberg (Franz-Penzoldt-Center). The animal procedures have been approved by the 'Regierung of Mittelfranken' and were conducted in accordance with the guidelines of Federation of European Laboratory Animal Science Associations (FELASA).

Analyses of immune cell infiltration by flow cytometry. For analyses of immune cell infiltration, the tumors were processed with a tumor dissociation kit (Miltenyi Biotec, Bergisch Gladbach, Germany). Afterwards, the cells were centrifuged with easycoll separating solution (Biochrom) to discard dead cells. The cells were then stained for $30 \mathrm{~min}$ at $4^{\circ} \mathrm{C}$ with the following fluorescence labeled antibodies: CD4-PCC5.5 (BD Pharmingen), CD8-PE (BD Pharmingen), CD3-V450 (BD Pharmingen), CD11C-PE (BD Pharmingen) and CD45.2-PCC5.5 (eBioscience). Determination of Tregs was performed with FoxP3 Staining Buffer Set and the antibodies CD4-Vioblue, CD25-AF488 and FoxP3-APC (Miltenyi
Biotec). Multicolor flow cytometry was performed with the Gallios Flow Cytometer (Beckman Coulter Inc.).

Analysis of specific T-cell activation by using OT1 mice and B16OVA melanoma cells. B16-Ova cells $\left(10^{6}\right)$ solved in $200 \mu$ l Ringer's solution were injected into the right shaved flank of female OT1 mice at day 0 . The tumors were treated as described above for the other mice. At day 14, the draining lymph nodes (axillary and inguinal) were removed and single cell suspensions were prepared with cell strainers (pore size of $70 \mu \mathrm{m}$ ). For detection of DCs present in the lymph nodes and presentation of the model tumor antigen, the cells were stained with CD11C-FITC (BD Pharmingen), CD8-APC (BD Pharmingen), OVA257-264 (SIINFEKL)-PE (eBioscience) and CD3-V450 (BD Pharmingen). T-cell activation was measured by analyzing intracellular IFN $\gamma$ after re-stimulation of the cells. For this, $2 \times 10^{6}$ cells were re-stimulated with OVA peptide $\left(10^{-7} \mathrm{M}\right)$ and Golgi Plug for $5 \mathrm{~h}$. Surface staining was performed with CD3-V450 (BD Pharmingen) and CD8-PE (BD Pharmingen) by incubating for $30 \mathrm{~min}$ at $4^{\circ} \mathrm{C}$. After washing, the cells were made permeable by addition of Cytofix/Cytoperm and incubation for $20 \mathrm{~min}$ at $4^{\circ} \mathrm{C}$. For intracellular staining, the antibody IFN $\gamma$-Pe-Cy7 (BD Pharmingen) was added and the cells were incubated for another $30 \mathrm{~min}$ at $4{ }^{\circ} \mathrm{C}$. The cells were washed and analyzed by multicolor flow cytometry with the Gallios Flow Cytometer (Beckman Coulter Inc.).

Statistical analyses. Graph pad prism (Version 5.04) was applied for statistical analysis with the Mann-Whitney $U$ test. Results were considered statistically significant for $P<0.05\left(^{*}\right)$ or (\#) and highly significant for $\left.P<0.01{ }^{* *}\right)$ or (\#\#).

\section{Conflict of Interest}

The authors declare no conflict of interest.

Acknowledgements. Part of this work was supported by the doctoral training program GRK1660 from the German Research Foundation (DFG) and by the German Research Foundation (GA 1507/1-1). We thank Prof Dr. Marco Idzko and Jessica Becker, Freiburg, Germany, for advices in performing the apyrase assays and Dr. Sennewald Medizintechnik GmbH for providing us the BSD50 apparatus for local hyperthermia treatment of tumor-bearing mice. We also thank Prof Dr. Roland Lang and Prof Dr. Thomas Winkler, both Erlangen, Germany, for providing us the MyD88 $\mathrm{KO}$ and RAG KO mice.

1. Dunn GP, Bruce AT, Ikeda H, Old LJ, Schreiber RD. Cancer immunoediting: from immunosurveillance to tumor escape. Nat Immunol 2002; 3: 991-998.

2. Obeid M, Tesniere A, Ghiringhelli F, Fimia GM, Apetoh L, Perfettini JL et al. Calreticulin exposure dictates the immunogenicity of cancer cell death. Nat Med 2007; 13: 54-61.

3. Hodge JW, Guha C, Neefjes J, Gulley JL. Synergizing radiation therapy and immunotherapy for curing incurable cancers. Opportunities and challenges. Oncology (Williston Park) 2008; 22: $1064-1070$.

4. Rubner Y, Wunderlich R, Ruhle PF, Kulzer L, Werthmoller N, Frey B et al. How does ionizing irradiation contribute to the induction of anti-tumor immunity? Front Oncol 2012; 2: 75.

5. Zitvogel L, Casares N, Pequignot MO, Chaput N, Albert ML, Kroemer G. Immune response against dying tumor cells. Adv Immunol 2004; 84: 131-179.

6. Voll RE, Herrmann M, Roth EA, Stach C, Kalden JR, Girkontaite I. Immunosuppressive effects of apoptotic cells. Nature 1997; 390: 350-351.

7. Gaipl US, Sheriff A, Franz S, Munoz LE, Voll RE, Kalden JR et al. Inefficient clearance of dying cells and autoreactivity. Curr Top Microbiol Immunol 2006; 305: 161-176.

8. Schulze C, Munoz LE, Franz S, Sarter K, Chaurio RA, Gaipl US et al. Clearance deficiencya potential link between infections and autoimmunity. Autoimmun Rev 2008; 8: 5-8.

9. Apetoh L, Ghiringhelli F, Tesniere A, Criollo A, Ortiz C, Lidereau R et al. The interaction between HMGB1 and TLR4 dictates the outcome of anticancer chemotherapy and radiotherapy. Immunol Rev 2007; 220: 47-59.

10. Ullrich E, Bonmort M, Mignot G, Kroemer G, Zitvogel L. Tumor stress, cell death and the ensuing immune response. Cell Death Differ 2008; 15: 21-28.

11. Fucikova J, Kralikova P, Fialova A, Brtnicky T, Rob L, Bartunkova J et al. Human tumor cells killed by anthracyclines induce a tumor-specific immune response. Cancer Res 2011; 71: 4821-4833.

12. Castiglioni A, Canti V, Rovere-Querini P, Manfredi AA. High-mobility group box 1 (HMGB1) as a master regulator of innate immunity. Cell Tissue Res 2011; 343: 189-199.

13. Yang D, Chen Q, Yang H, Tracey KJ, Bustin M, Oppenheim JJ. High mobility group box-1 protein induces the migration and activation of human dendritic cells and acts as an alarmin. $J$ Leukoc Biol 2007; 81: 59-66.

14. Park JS, Svetkauskaite D, He Q, Kim JY, Strassheim D, Ishizaka A et al. Involvement of tolllike receptors 2 and 4 in cellular activation by high mobility group box 1 protein. $J$ Biol Chem 2004; 279: 7370-7377. 
15. Dumitriu IE, Bianchi ME, Bacci M, Manfredi AA, Rovere-Querini P. The secretion of HMGB1 is required for the migration of maturing dendritic cells. J Leukoc Biol 2007; 81: 84-91.

16. Krysko O, Love Aaes T, Bachert C, Vandenabeele P, Krysko DV. Many faces of DAMPs in cancer therapy. Cell Death Dis 2013; 4: e631.

17. Aymeric L, Apetoh L, Ghiringhelli F, Tesniere A, Martins I, Kroemer $G$ et al. Tumor cell death and ATP release prime dendritic cells and efficient anticancer immunity. Cancer Res 2010; 70: 855-858.

18. Ma Y, Shurin GV, Peiyuan Z, Shurin MR. Dendritic cells in the cancer microenvironment. $J$ Cancer 2013; 4: 36-44

19. Moyer JS, Li J, Wei S, Teitz-Tennenbaum S, Chang AE. Intratumoral dendritic cells and chemoradiation for the treatment of murine squamous cell carcinoma. J Immunother 2008; 31: 885-895.

20. Teitz-Tennenbaum S, Li Q, Okuyama R, Davis MA, Sun R, Whitfield J et al. Mechanisms involved in radiation enhancement of intratumoral dendritic cell therapy. $\mathrm{J}$ Immunother 2008; 31: 345-358.

21. Fadul CE, Fisher JL, Hampton TH, Lallana EC, Li Z, Gui J et al. Immune response in patients with newly diagnosed glioblastoma multiforme treated with intranodal autologous tumor lysate-dendritic cell vaccination after radiation chemotherapy. J Immunother 2011; 34 382-389.

22. Krawczyk PM, Eppink B, Essers J, Stap J, Rodermond H, Odijk H et al. Mild hyperthermia inhibits homologous recombination, induces BRCA2 degradation, and sensitizes cancer cells to poly (ADP-ribose) polymerase-1 inhibition. Proc Natl Acad Sci USA 2011; 108: 9851-9856

23. Frey B, Weiss EM, Rubner $Y$, Wunderlich R, Ott OJ, Sauer $R$ et al. Old and new facts about hyperthermia-induced modulations of the immune system. Int $J$ Hyperthermia 2012; 28: 528-542

24. Anvekar RA, Asciolla JJ, Lopez-Rivera E, Floros KV, Izadmehr S, Elkholi R et al. Sensitization to the mitochondrial pathway of apoptosis augments melanoma tumor cell responses to conventional chemotherapeutic regimens. Cell Death Dis 2012; 3: e420.

25. Zitvogel L, Kroemer G. Oncolmmunology: a new journal at the frontier between oncology and immunology. Oncoimmunology 2012; 1: 1-2.

26. Vandenabeele P, Galluzzi L, Vanden Berghe T, Kroemer G. Molecular mechanisms of necroptosis: an ordered cellular explosion. Nat Rev Mol Cell Biol 2010; 11: 700-714.

27. Vanden Berghe T, Vanlangenakker N, Parthoens E, Deckers W, Devos M, Festjens N et al. Necroptosis, necrosis and secondary necrosis converge on similar cellular disintegration features. Cell Death Differ 2010; 17: 922-930.

28. Vercammen D, Beyaert R, Denecker G, Goossens V, Van Loo G, Declercq W et al. Inhibition of caspases increases the sensitivity of L929 cells to necrosis mediated by tumor necrosis factor. J Exp Med 1998; 187: 1477-1485.

29. Christofferson DE, Yuan J. Necroptosis as an alternative form of programmed cell death. Curr Opin Cell Biol 2010; 22: 263-268.

30. Friedlander RM. Apoptosis and caspases in neurodegenerative diseases. $N$ Engl $J$ Med 2003; 348: 1365-1375.

31. Moretti L, Kim KW, Jung DK, Willey CD, Lu B, Hwang M et al. Radiosensitization of solid tumors by Z-VAD, a pan-caspase inhibitor. Mol Cancer Ther 2009; 8: 1270-1279.

32. Ko SH, Ueno T, Yoshimoto Y, Yoo JS, Abdel-Wahab OI, Abdel-Wahab Z et al. Optimizing a novel regional chemotherapeutic agent against melanoma: hyperthermia-induced enhancement of temozolomide cytotoxicity. Clin Cancer Res 2006; 12: 289-297.

33. Los M, Gibson SB. Apoptotic Pathways as Targets for Novel Therapies in Cancer and Other Diseases. Springer: US, 2005.

34. Triantopoulou S, Efstathopoulos E, Platoni K, Uzunoglou N, Kelekis N, Kouloulias V. Radiotherapy in conjunction with superficial and intracavitary hyperthermia for the treatment of solid tumors: survival and thermal parameters. Clin Transl Oncol 2012; 21: 21.

35. Zitvogel L, Apetoh L, Ghiringhelli F, André F, Tesniere A, Kroemer G. The anticancer immune response: indispensable for therapeutic success? J Clin Invest 2008; 118: 1991-2001.

36. Schnorrer P, Behrens GM, Wilson NS, Pooley JL, Smith CM, El-Sukkari D et al. The dominant role of $\mathrm{CD} 8+$ dendritic cells in cross-presentation is not dictated by antigen capture. Proc Natl Acad Sci USA 2006; 103: 10729-10734.

37. Khan N, Khan MK, Almasan A, Singh AD, Macklis R. The evolving role of radiation therapy in the management of malignant melanoma. Int J Radiat Oncol Biol Phys 2011; 80 : 645-654

38. Overgaard J, Gonzalez Gonzalez D, Hulshof MC, Arcangeli G, Dahl O, Mella O et al. Hyperthermia as an adjuvant to radiation therapy of recurrent or metastatic malignant melanoma. A multicentre randomized trial by the European Society for Hyperthermic Oncology. Int J Hyperthermia 1996; 12: 3-20.

39. Wolter KG, Verhaegen M, Fernandez Y, Nikolovska-Coleska Z, Riblett M, de la Vega CM et al. Therapeutic window for melanoma treatment provided by selective effects of the proteasome on Bcl-2 proteins. Cell Death Differ 2007; 14: 1605-1616.

40. Jendrossek V. The intrinsic apoptosis pathways as a target in anticancer therapy. Curr Pharm Biotechnol 2012; 13: 1426-1438.

41. Iwata A, Morgan-Stevenson V, Schwartz B, Liu L, Tupper J, Zhu X et al. Extracellular BCL2 proteins are danger-associated molecular patterns that reduce tissue damage in murine models of ischemia-reperfusion injury. PloS One 2010; 5: e9103.

42. Shiffman ML, Pockros P, McHutchison JG, Schiff ER, Morris M, Burgess G. Clinical trial: the efficacy and safety of oral PF-03491390, a pancaspase inhibitor - a randomized placebo- controlled study in patients with chronic hepatitis C. Aliment Pharmacol Ther 2010; 31: 969-978.

43. Palumbo S, Comincini S. Autophagy and ionizing radiation in tumors: the "survive or not survive" dilemma. J Cell Physiol 2013; 228: 1-8.

44. Tapia IJ, Aris M, Arriaga JM, Blanco PA, Mazzobre F, Vega J et al. Development of a novel methodology for cryopreservation of melanoma cells applied to CSF470 therapeutic vaccine. Cryobiology 2013; 67: 163-169.

45. Lauber K, Bohn E, Krober SM, Xiao YJ, Blumenthal SG, Lindemann RK et al. Apoptotic cells induce migration of phagocytes via caspase-3-mediated release of a lipid attraction signal. Cell 2003; 113: 717-730.

46. Wu YT, Tan HL, Huang Q, Sun XJ, Zhu X, Shen HM. zVAD-induced necroptosis in L929 cells depends on autocrine production of TNFalpha mediated by the PKC-MAPKs-AP-1 pathway. Cell Death Differ 2011; 18: 26-37.

47. Murphy JM, Czabotar PE, Hildebrand JM, Lucet IS, Zhang JG, Alvarez-Diaz S et al. The pseudokinase MLKL mediates necroptosis via a molecular switch mechanism. Immunity 2013; 39: 443-453.

48. Weiss EM, Wunderlich R, Ebel N, Rubner Y, Schlucker E, Meyer-Pittroff R et al. Selected anti-tumor vaccines merit a place in multimodal tumor therapies. Front Oncol 2012; 2: 132.

49. Pisetsky DS. The translocation of nuclear molecules during inflammation and cell death. Antioxidants \& redox signaling 2014; 20: 1117-1125.

50. Vezzoli M, Castellani P, Corna G, Castiglioni A, Bosurgi L, Monno A et al. High-mobility group box 1 release and redox regulation accompany regeneration and remodeling of skeletal muscle. Antioxid Redox Signal 2011; 15: 2161-2174.

51. Park JS, Gamboni-Robertson F, He Q, Svetkauskaite D, Kim JY, Strassheim D et al. High mobility group box 1 protein interacts with multiple Toll-like receptors. Am J Physiol Cell Physiol 2006; 290: C917-C924.

52. Akira S, Takeda K. Functions of toll-like receptors: lessons from KO mice. C R Biol 2004; 327 : 581-589.

53. Laliberte JF, St-Jean P, Beaudoin AR. Kinetic effects of $\mathrm{Ca} 2+$ and Mg2+ on ATP hydrolysis by the purified ATP diphosphohydrolase. J Biol Chem 1982; 257: 3869-3874.

54. Cauwels A, Rogge E, Vandendriessche B, Shiva S, Brouckaert P. Extracellular ATP drives systemic inflammation, tissue damage and mortality. Cell Death Dis 2014; 5: e1102.

55. Garcia-Calvo M, Peterson EP, Leiting B, Ruel R, Nicholson DW, Thornberry NA. Inhibition of human caspases by peptide-based and macromolecular inhibitors. J Biol Chem 1998; 273: 32608-32613.

56. Umansky V, Shevchenko I, Bazhin AV, Utikal J. Extracellular adenosine metabolism in immune cells in melanoma. Cancer Immunol Immunother 2014; 63: 1073-1080.

57. den Haan JM, Lehar SM, Bevan MJ. CD8(+) but not CD8(-) dendritic cells cross-prime cytotoxic T cells in vivo. J Exp Med 2000; 192: 1685-1696

58. Demaria S, Ng B, Devitt ML, Babb JS, Kawashima N, Liebes $L$ et al. lonizing radiation inhibition of distant untreated tumors (abscopal effect) is immune mediated. Int $\mathrm{J}$ Radiat Oncol Biol Phys 2004; 58: 862-870.

59. Golden EB, Demaria S, Schiff PB, Chachoua A, Formenti SC. An abscopal response to radiation and ipilimumab in a patient with metastatic non-small cell lung cancer. Cancer Immunol Res 2013; 1: 365-372.

60. Postow MA, Callahan MK, Barker CA, Yamada Y, Yuan J, Kitano S et al. Immunologic correlates of the abscopal effect in a patient with melanoma. N Engl J Med 2012; 366: 925-931.

61. Schildkopf P, Frey B, Ott OJ, Rubner Y, Multhoff G, Sauer R et al. Radiation combined with hyperthermia induces HSP70-dependent maturation of dendritic cells and release of proinflammatory cytokines by dendritic cells and macrophages. Radiother Oncol 2011; 101: 109-115.

62. Schleicher U, Bogdan C. Generation, culture and flow-cytometric characterization of primary mouse macrophages. Methods Mol Biol 2009; 531: 203-224.

63. Lutz MB, Kukutsch N, Ogilvie AL, Rossner S, Koch F, Romani N et al. An advanced culture method for generating large quantities of highly pure dendritic cells from mouse bone marrow. J Immunol Methods 1999; 223: 77-92.

64. Geran RI, Greenberg NH, Macdonald MM, Abbott BJ. Modified protocol for the testing of new synthetics in the L1210 lymphoid leukemia murine model in the DR\&D program, DCT, NCl. Natl Cancer Inst Monogr 1977: 151-153.

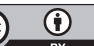

Cell Death and Disease is an open-access journal published by Nature Publishing Group. This work is licensed under a Creative Commons Attribution 4.0 International License. The images or other third party material in this article are included in the article's Creative Commons license, unless indicated otherwise in the credit line; if the material is not included under the Creative Commons license, users will need to obtain permission from the license holder to reproduce the material. To view a copy of this license, visit http://creativecommons.org/licenses/by/4.0/ 